\section{SYPHILIS AND VENEREAL DISEASES}

\section{AS A PUBLIC HEALTH PROBLEM *}

H. G. IRVINE, M.D.

Director of the Division of Venereal Diseases, Minnesota State Board of Health; Assistant Professor of Dermatology and Syphilis, University of Minnesota Medical School; Director, Bureau of Venereal Diseases, California State Board of Health, October, 1917, to April, 1918

\section{MINNEAPOLIS}

Health authorities ought to be concerned with all diseases which, being infectious and communicable, are likely, through their spread, to endanger public health. It is said that the knowledge necessary to control such a disease consists of the recognition of the causative germ, its method of being carried and the having of a specific therapy. For years we have known the germs of syphilis and gonorrhea, have been perfectly cognizant of how both diseases are carried, and have had at hand a more or less specific therapy. More than that, we have known that continence is entirely consistent with health, and that it is an almost sure preventive of both diseases; and yet, we have hesitated as individuals and as a profession to go on record for it. We have even hesitated, and perhaps with good reason, to advocate those well known artificial means of prevention which the Army and Navy have demonstrated to be so valuable.

The public at large has been inclined to discount what seemed to it unbelievable figures of the prevalence, and the havoc wrought by venereal disease, and has not shown a willingness to be informed, in plain language, of all the facts. This has led to the nefarious practice of making these diseases "secret diseases," in fact as well as in name, and with a full knowledge that a goodly proportion of innocent persons were constantly being infected, we still have tolerated this policy of silence. It has taken a war to wake us up and make it possible to attempt to handle these diseases along the same lines that other infectious and conmunicable diseases are handled. The government knows full well that we must have well soldiers if we would win this war; it also knows that with every war there has been a marked increase in venereal diseases, and that the control of these diseases among the enlisted men would be its greatest disease problem. These facts were given full recognition when, early in the war, a very definite and complete program was adopted for the early diagnosis, treatment and control of venereal diseases. Not, however, until the mobilization of our draft Army did any one fully realize the very great need of the rapid extension of a similar program to the civil population. When it was seen from the figures produced that the venereal disease rate of civilians was several times greater than had been the rate in the Regular Army, the War Department, particularly through the SurgeonGeneral's Office began to call on the public health officials of various states to undertake definite campaigns to control these diseases. The fact that nearly every family in the land has had or will have a very personal interest in our Army makes the public sympathetic to this work as it has never been before.

California was, I think, the first state to answer the call, and made an appropriation, from war emergency funds, of $\$ 60,000$ for the organization of a bureau

* Read before the Section on Dermatology at the Sixty-Ninth Annual Session of the Americal Medical Association, Chicago, June, 1918. of venereal diseases in the state board of health. Minnesota followed a few months later with an appropriation of $\$ 35,000$ for the creation of a similar division. In both cases the funds are to run to the next meeting of the legislatures; for California this means two years; for Minnesota, one year.

In all of the work, one fundamental fact has been kept in view, namely, the absolute need of recognizing the complexity of the problem and of coordinating the work of all groups interested in any particular angle of the attack. Generally speaking, this is in contrast to any previous method under which all of us have seen failures registered because of the necessary limitations.

\section{PROGRAM OF ATTACK}

The program for a state divides itself logically into four parts. These will be considered in the order of their importance from the standpoint of their effect on the reduction of disease. The first three parts are concerned with the control of three distinct groups of patients, the fourth part with educational work.

\section{THE CARRIER}

The first group of patients with which we are concerned is the one in which enforced quarantine and treatment are necessary. Here are included the great carriers of these diseases, the prostitute, both professional and clandestine, prisoners and inmates of institutions, and incorrigible patients. So far as pros-

\begin{tabular}{|c|c|c|c|c|c|}
\hline FFECT OF & LAW EN & $\mathrm{NFO}$ & ON & YRF & ID \\
\hline & & INFECTIONS & & & \\
\hline Mopth & & $\begin{array}{l}\text { Mean Strength } \\
\text { of Command }\end{array}$ & $\begin{array}{c}\text { Diseases, } \\
\text { New Cases }\end{array}$ & $\begin{array}{r}\text { Rep } \\
\text { by Prol } \\
\text { Tre }\end{array}$ & $\begin{array}{l}\text { resented } \\
\text { phylactic } \\
\text { atments }\end{array}$ \\
\hline October & & . 13,813 & 193 & & 951 \\
\hline ember & & 16 , & 10 & & 669 \\
\hline December & & 17 & 124 & & 623 \\
\hline January & & 18,068 & 61 & & 378 \\
\hline ebruary & & 17,315 & 86 & & 478 \\
\hline
\end{tabular}

titution is concerned, there must be active cooperation of the police departments and courts in suppressing as far as possible all prostitution. This action will make prostitutes inaccessible, and so reduce exposures; reduction of exposures is bound to reduce infections. Examinations should be made in all cases and quarantine instituted in a hospital or other suitable place.

The effect of this work is very nicely demonstrated by some figures collected in San Francisco. ${ }^{1}$ In the first place, the problem was rapidly reduced, as shown by the fact that in October before the work started, nearly 400 women were brought into court on charges of moral turpitude. Soliciting on the streets was rampant. November 1, arrangements were made for jail sentences in all cases with quarantine and treatment of those found diseased. During November only about 150 appeared in court, and the streets were clean. The number continued to decrease, until in February less than 100 were arrested.

The effect on exposures and infections is shown by the accompanying table in which it is seen that in the first month exposures, which may be represented by prophylactic treatments, were reduced nearly 300 , while infections were practically cut in two, and this in spite of the fact that the strength of command shows an increase of nearly 3,000. As time went on, many other elements undoubtedly entered into the reduction; but there was apparently no other explanation

1. Statistics compiled by Lieut. Allison T. French, Sanitary Corps, U. S. N. A 
for this rapid reduction taking place immediately following law enforcement. Another point to be emphasized in the table is that in February the same judge was on the bench as in October, and he was the one of the four who rotated in this court who was most reluctant in agreeing to the government's demands. Consequently, we see during his month an increase in exposures and a corresponding increase in infections. This table apparently demonstrates that, to a certain extent, exposures and infections follow the enforcement or nonenforcement of law.

While this law enforcement will have a deterrent effect on a certain number of prostitutes, it should not be understood that the work ends with this or their medical treatment; if it did, it would be wasted since on release they would immediately return to their profession and become reinfected. It will be necessary that adequate provision be made for the permanent custodial care of the feebleminded, and for those confirmed offenders who can be forced into a life of decency only by long term commitments to reformatories. By bringing proper social service agencies in contact with the younger offenders, they may almost immediately be returned to society.

The professional prostitute is a prolific spreader of disease, as she nearly always has gonorrhea, which may be chronic in nature, and particularly because, if allowed to practice her profession openly, she daily exposes from ten to twenty or more patrons. From the standpoint of syphilis she is not so important, as she contracts it early in her career and thereafter is likely to take sufficient treatment to keep the disease under control. Clandestine prostitutes are a danger, not so much on account of the number of persons they expose individually, but because there are a great many more of them, and being youthful offenders, they are more likely to be acutely infected and less well informed as to the care of themselves and their patrons.

In the examination of several hundred prostitutes in San Francisco, Sperry ${ }^{2}$ found only two or three with demonstrable lesions of syphilis. In an examination of 731 women, Stevens ${ }^{3}$ found 147 infected with gonorrhea, 243 with syphilis, and ninety-six with both syphilis and gonorrhea.

In carrying out this work in California, nearly $\$ 100,000$ was appropriated by various communities of the state, and special isolation hospitals were built in San Diego and Los Angeles. The one in San Diego has thirty-five beds, and the one in Los Angeles, fifty-four beds. San Francisco arranged for a ward of thirty beds in the San Francisco Hospital, and a budget has recently been passed for approximately $\$ 50,000$ for next year, which not only will permit the carrying on of this work in the hospital, but also will provide for a place of detention at the County Relief Home, which will care for from fifty to 100 inmates. Many of the smaller communities of the state have arranged for the detention of such patients in their county hospitals. Generally speaking, there is greater need for places of detention with proper hospital facilities than there is for straight hospital quarters, as many of these persons are properly ambulatory patients.

There should be an effort to make investigations of appropriate groups, and institute treatment when

2. Sperry, J. A.: Venereal Disease Control in San Francisco by the Board of Health, California State Jour. Med.. 1918, 16, 120. 3. Stevens, W. E.: Gonorrhea in Women, California State Jour. indicated. In most cases state prisons provide aclequate hospital and medical facilities, but rarely do we find any attempt made to examine and treat prisoners in city and county jails. Here we have a class of people who are naturally prone to have no regard for the rights of others, and who are likely to have syphilis or gonorrhea. Arrangements should be made for a careful examination, including a Wassermann test of every prisoner, and proper treatment instituted. If necessary, cases should be quarantined beyond the time of sentence, so that in no case would an individual be allowed his freedom while still in an infectious condition.

During the months of February and March there were examined in the city and county jail in Los Angeles 681 male and female prisoners, 389 of whom were infected, and more than 7,000 treatments were given.

An examination was recently made of forty-three women and 145 men in the Minneapolis City Workhouse. Of the women, fourteen had gonorrhea, nineteen positive Wassermanns, and six had both syphilis and gonorrhea. Of the men, seven had gonorrhea, fifty had positive Wassermanns, and two had both syphilis and gonorrhea, thus making a total of seventyseven diseased persons out of 188 examined. In general, when surveys have been made of the inmates of jails, approximately 20 per cent. have been found to have syphilis, and nearly 50 per cent. to have syphilis or gonorrhea. These figures indicate the great need that this work be undertaken with this class of people, who, we must realize, will not take the care of themselves necessary to prevent infecting others.

\section{DISPENSARY PATIENTS}

Investigations have shown that not more than from 30 to 50 per cent. of the patients infected with gonorrhea or syphilis receive adequate medical service at the hands of private practitioners. This has been due partly to the fact that many physicians are not sufficiently trained in the care of these diseases, and partly to the fact that a great many patients coming to them could not afford to pay for sufficient treatment to arrive at a cure. It is also a fact that a large number of patients, particularly of the poorer classes, go to drug stores, and, of course, it is obvious that treatment received in this way is worthless.

Investigations of certain dispensaries in the East have shown that approximately 50 per cent. of their men patients with gonorrhea attempt drug store treatment before they come to the dispensary.

If there is an insufficient number of specially trained physicians, and if the majority of the people cannot afford to pay the fees of specialists, it is perfectly obvious that there is a great need for more and better dispensary facilities, where people can obtain either free, or for a nominal sum, expert services. We should remember in this regard that we are not concerned entirely with the individual patient, but that to a certain extent we are providing for him in order properly to protect the community. The fact must also be emphasized that unless all of these cases are treated until cured, not very much is accomplished from the public health standpoint. This, of course, is more true of gonorrhea than of syphilis, since the one is infectious so long as present, whereas the other may be rendered temporarily noninfectious. But the great need is to place patients in such a condition that 
they will not be dangerous to others, and this means, generally speaking, a cure.

The man or woman who can afford to pay for only a little treatment should be sent at once to a dispensary or hospital where sufficient and expert treatment may be received.

Pressure should be brought to bear to see to it that every hospital supported by public funds admits all syphilis and gonorrhea patients on exactly the same basis as other patients are admitted, as there would seem to be no sense in their refusing on the one hand to admit active cases of gonorrhea or syphilis, while on the other hand, it is a fact that their wards are continually filled with the end-results of both of these diseases.

The problem of dispensaries is more acute in many of the smaller cities of 40,000 or 50,000 population than it is in the larger cities where there are already in operation either city or university clinics. It is being proposed, therefore, in many of the states, that a number of dispensaries be established in proper places throughout the state, either directly under the state board of health, or, at least, stimulated and officially recognized by it. In states in which there is a sufficient appropriation, a subsidy will be granted communities to assist in establishing these dispensaries, and it is quite possible that by making a nominal charge for treatment the dispensaries can be almost self-supporting.

In nearly all states in which the work is going on, provision is made for free arsphenamin, and these clinics can be made the official distributing points for this treatment. This plan is in accordance with the program that is being followed by Great Britain, namely, that of the federal government stimulating the organization of such clinics, and providing for 75 per cent. of the expenses, while the local communities take care of the other 25 per cent.

Unless the work of these and all other dispensaries is developed to conform to certain standards, the results will hardly be a success. But if certain standards are required such as the provision of a trained staff, sufficient rooms and equipment, nurses and social service workers, good results are almost bound to be attained. There are two distinct ways of insisting that these dispensaries be run according to standards laid down by the state board of health. In many states the board of health has the power to license dispensaries, and definitely control them, and in others, it will be possible by withholding official recognition, or by withholding the free arsphenamin, to see that the standards are followed.

It is very important that the states supply free laboratory service for the diagnosis of both gonorrhea and syphilis.

In California many local health departments were already operating dispensaries in connection with their work, and in many of these a department of venereal diseases was added. In San Diego such an outpatient department was instituted for both men and women. In Los Angeles an evening clinic for men was already in operation, and this has been enlarged, with very much better equipment, and now provides adequate service for both men and women. In May this clinic registered forty-six new cases, and had a total of 136 patients under treatment. San Francisco has depended in the past on the dispensaries of several medical schools. Their new budget, which has been granted, provides for a day and evening outpatient clinic for both men and women at the San Francisco Hospital. In Fresno the county hospital arranged for a ward for venereal diseases, and instituted an outpatient service, with a proper social service department, and within a month's time had thirty-five cases of syphilis under treatment. In Bakersfield a similar arrangement was made at the county hospital. In Santa Barbara a new contagious disease hospital is near completion, and arrangements have been made to have a portion of this devoted to venereal diseases. In Oakland and Sacramento the local health departments have both inaugurated clinics for venereal diseases.

In Minnesota arrangements are being made to open a municipal dispensary in St. Paul. The City and County Hospital already provides about twenty-five beds for venereal disease patients. In Minneapolis the University Dispensary has adequate clinics for syphilis and gonorrhea, and the University Hospital has recently set aside twelve beds for these patients. In Duluth a clinic will probably be established under the local health department. Arrangements have been completed in these three cities for examination of all police court cases, and their quarantine and treatment when necessary.

In connection with these dispensaries, and cases placed under quarantine from the courts, there was distributed up to March 31, 1918, in California 1,660 doses of arsphenamin. This was distributed to thirtytwo different dispensaries or health departments, and was given to 393 patients. For the most part, these were a class of people who under former conditions would have received no treatment. In view of the fact that these patients received an average of more than four doses of arsphenamin within this rather brief period, it is felt that a piece of work worth while has been accomplished. These patients also received mercury by inunction or injection.

\section{PRIVATE PATIENTS}

Adequate provision must be made for the treatment, and especially for the control, of private as well as indigent patients. This necessitates the passing of laws or rules and regulations, by the state board of health, under which these patients can be required to take the necessary amount of treatment.

There should be a system of notification identifying in some way those persons venereally diseased, and providing for a report of the name and address of the individual who does not so conduct himself as not to endanger others. The health officers should be responsible for the control of these individuals when they are reported. A rule should also provide for parents and guardians being responsible for the compliance of minors. In all cases reports are strictly confidential. Many physicians believe that notification is bad, as it is thought that it will have a tendency to drive patients away from them, and into the hands of druggists and quacks. The public in general, and patients in particular, should be informed carefully of the confidential nature of these reports, and that so long as they as patients continue under treatment and conform to the necessary rules and regulations, their names and addresses need not be divulged, nor will there be any difference in the relationship to their physician on account of this work.

California has had for several years a law requiring the reporting of these cases by number, but no definite effort ever has been made to enforce it. Since the 
campaign was undertaken, however, their reporting has increased to more than three times the amount for the previous year. In Minnesota we are just preparing to inaugurate this work by circularizing all the physicians and asking their support for the government program. Many states in which reporting is now going on report the complete cooperation of the medical profession.

So far as we are concerned with the druggists, rules should be passed which will prevent counter prescribing, or the sale of any preparation or nostrum in the treatment of syphilis or gonorrhea. This sort of treatment means the loss of a considerable amount of time to the patient, and also in most cases it means that the patient, when finally presenting himself to a physician, has a chronic, difficult case, rather than an early case in which proper treatment can be very much more successfully given.

There is also a point in connection with this which distinctly concerns the Army and Navy, and indirectly also the civil population, and this is the treatment of soldiers or sailors by drug stores. This is to be condemned for two reasons. In the first place, on account of the men themselves getting inadequately treated, and in the second place, because it prevents the Army surgeon from placing these men under control, since the rules in the Army and Navy are that no such infectious patient be granted a leave of absence from the camp, and in that way any infection to the civil population is prevented.

By preventing the advertising of quacks, and by proper education of the people, it would seem possible to put the obvious quack or faker out of business. But it will be rather more difficult to restrain certain otherwise reputable physicians who persist in practically labeling themselves "quacks" so far as venereal diseases are concerned, by agreeing to cure these diseases quickly for stated fees. Generally speaking, the control of these patients who go to private practitioners depends almost entirely on the hearty cooperation of the medical profession, both individually and collectively. It is to be hoped, particularly at this time, when the value of this work to the federal government is so great, by reducing the disability among soldiers and sailors, both present and prospective, and among the vast army of industrial workers, that all physicians will pledge themselves to this cooperation.

\section{EDUCATION}

The systematic education of both laity and physicians as to the danger of these diseases, to their prevalence, and to the needs of adequate treatment, is the most important of any single method of attack. This should be directed along two distinct lines. In the first place, a campaign should be undertaken to get information to both laity and physicians from the disease standpoint. This should include lectures, distribution of pamphlets, setting up of placards in public comfort stations and other appropriate places, and various other means of publicity. Lectures should be given to various groups of men and women, and to county medical societies, both relative to the diseases and to the program for their control. A pamphlet on the treatment of these diseases should be furnished to physicians, as well as one containing information and instructions to be given patients. A carefully planned exhibit and stereomotorgraph with proper slides may also be used very successfully in various communities.
The other part of the educational work is directed toward those who in turn will be teachers, and is not limited in its scope entirely to venereal diseases. Courses should be arranged for in every state university, and in all normal schools. These courses should cover biology, psychology of sex, sociology, sex hygiene and venereal diseases. Courses should be given in medical schools with particular reference to the public health side of the problem. Courses should be given to hospital, public health and school nurses. Under the educational department a course of study of sex education should be planned for parents' and teachers' associations. Communities should be stimulated to the further use of present recreational facilities. The need and the part this work plays in stimulating a normal sex life in the young should be emphasized. This is particularly a great need in the rural communities.

I believe one important detail of the educational work should be giving people to understand that something can be done if exposure has already taken place. This may be called early treatment, or prophylaxis, as one wills. Its value has been fully demonstrated by the Army; of that there can be no question; but there is the question as to how this information should be given. I myself believe such information should be given individuals at the time of their attendance to the hospital or dispensary, and that people should be urged to go to these places for advice; but I do not believe that the public in general is willing to have such information spread broadcast to the youth of the land, nor do I believe that it would be proper on our part to advocate the sale of a prophylactic package, since that savors of the very drug store treatment that we are attempting to discard.

In connection with the educational work in California, forty lectures were given in cooperation with the War Department's Commission on Training Camp Activities, which reached approximately 55,000 enlisted men. A limited number of lectures were given to certain groups of people throughout the state, and a definite campaign for work along this line has been outlined. A number of sets of posters furnished by the American Social Hygiene Society were placed in various Army and Navy camps. A stereomotorgraph with proper slides was purchased, and sent first to Camp Kearney, at that time the largest cantonment in the state, and from there to others in different localities. Approximately 2,000 placards with information on venereal diseases were distributed and placed in the latrines of the Army and Navy camps of the state. Approximately 1,600 were distributed and placed by local health officers. About 6,000 pamphlets on venereal diseases, and 5,000 on the modern treatment of syphilis, were distributed throughout the state during the six months' period.

In Minnesota we feel that our educational program is well under way in view of the time elapsed. During the past winter complete courses were given at the university, and at a number of the normal schools of the state. Dr. Ulrich, who has charge of this work, has given fifty-five lectures to approximately 10,000 people. A number of different pamphlets have been issued and are being distributed. An exhibit is being planned and a stereomotorgraph with complete sets of slides has been ordered. A copy of the War Department's film "Fit to Fight" has also been ordered and will be shown to all enlisted men. 


\section{CONCLUSIONS}

The program as proposed, and as put into force by the War Department, has already been proved a success by the fact that our armies now have the lowest venereal disease rate of any army in the field, and for weeks the rate of the expeditionary forces has been only about half that formerly averaged by our Regular Army. The program as proposed for civilians is along the same lines and is intended to be carried out in cooperation with the Army and Navy. There is every reason to believe that it will also be successful, particularly if it receives the support of the profession. There is a good opportunity for the private practitioner to show his desire to help by complying with all rules and regulations and by doing as much individual educational work as possible. The specialist who does not enter the Medical Reserve corps has an opportunity to serve at home by taking an active part in this movement, by lending his assistance with his special training, not only in working out problems, but by giving some time to dispensary work in his community.

There is need for the federal government to come to the state's aid in the way of finances just as England has done, and such legislation is now before Congress. With this assistance, the work will go on much more rapidly.

Emphasis should be placed on the educational work, particularly in the medical schools, as the people at large depend on the physicians for information concerning these diseases, and unfortunately the majority of the medical profession have little idea of the modern conception of sex hygiene or the public health point of view of the problems of prostitution and venereal diseases. This is due primarily to a lack of teaching of these subjects in the medical colleges.

A well rounded progiam for combating venereal diseases must take cognizance of every factor that enters into their spread. Any attempt to limit the work to any one field will fail, just as medical efforts at reducing venereal disense through attempted regulation of prostitution has always failed. In its last analysis we must agree with Surgeon-General Gorgas that venereal diseases depend on sex immorality for their spread; and until we do away entirely with immoral sexual relations, we cannot do away entirely with these diseases.

601 Syndicate Building.

\section{ABSTRACT OF DISCUSSION}

ON PAPERS OF DRS. PUSEY, FORDYCE AND IRVINE

Dr. John E. Lane, New Haven, Conn.: The work which Dr. Pusey and his associates have done has already given such definite results and has been demonstrated to be of so great value that it cannot help assisting in the adoption, by other states, of the plan suggested by Dr. Irvine for the proplyylactic measures which he has already introduced in several states. It is interesting to know that the value of the prophylactic measures adopted in our Army has already been recognized in France. You may remember that Fournier, in 1901, established the Society of Sanitary and Moral Prophylaxis in Paris, and planned prophylaxis on the lines that we have adopted. The measures suggested have never been taken very seriously by the majority of French physicians. A short time ago Sabouraud visited our army camps in France and gave a most flattering report of the result of the prophylactic methods used by our Army. He at the same time deplored the fact that the French, who first originated the plan and methods of prophylaxis, had to be shown how to put them in.to operation by the Americans.
We are all indebted:to Dr. Fordyce for his insistence on the need of examination of the spinal fluid in cases of syphilis and for his persistence in demonstrating this need. We are also indebted to him for his persistence in demonstrating the need for organized hospital and dispensary facilities for the treatment of syphilis. It must be a cause of gratification to him to see that his efforts are beginning to bear fruit.

Dr. Irvine has been one of the leaders in the movement for getting the venereal diseases under the control of the state health authorities. The value of his work is best shown by the fact that several states have adopted plans similar to those which he has put into execution. I am glad to say that my own state is one of them.

Dr. John H. Stokes, Rochester, Minn.: I have myself been converted from a stand of opposition to intraspinal medication to the point where, while not an enthusiast, I am prepared to admit that at the hands of a man like Dr. Fordyce it is possible to produce results which cannot be duplicated by the conventional methods. On the other hand, I still feel that intraspinal therapy is a final rather than a first resort and that it should not be undertaken by the tyro. At the hands of the profession at large intradural therapy has been sadly overdone. This, however, is by no means a reflection on the method, but rather on those who have let enthusiasm get the better of their discretion. The results mentioned by Dr. Pusey and Dr. Irvine have interested me greatly. My personal hope is that state programs, however excellent, will not be allowed to overshadow the need for a really national campaign against venereal diseases.

Dr. KING SmITh, Toronto: Men with well-marked psoriasis should not be taken into the Army. They live in huts and tents with other men and often such men are put down as syphilitic and their life is miserable. It is the same with many other diseases. Many cases of typical psoriasis and other diseases are considered syphilis, and it is hard to change the diagnosis. The soldier's pay is altered, as you know, and that man does not start in with a fair chance. I would like to suggest to Dr. Pusey that they think of the returned men. They will soon be scnt back in great numbers with the loss of a leg or an arm and syphilis. The man cannot be kept in the Army, and you must find some way in which those men can be treated thoroughly in a civilian capacity. In Canada we have formed a league whereby these men can be gotten out of uniform but still receive care. The more you serve the more you will protect your other countrymen. You must give them every chance in this game, for they have given up everything for us, and we must protect them and when possible train the men not to put down syphilis against a man's name until he is sure of it. Get him back to the base hospita1 where he can have thorough treatment, and then make the diagnosis.

Many diseases have been put down to nervous origin. I found thousands of such cases soon after the evacuation of Gallipoli, where I happened to be. I saw only a very few irritated cases, never a lichen planus, and what struck me was the marked absence of nervous disease after going through that great campaign. The great thing I saw was the ecthyma group, which is often put down as syphilis. The men necessarily cannot change their clothes, the pediculosis is extreme and the ecthymoid conditions are very severe, forming great ulcers which look like tertiary syphilis, but are not. We sometimes do a routine Wassermann on a returned man, but I do not think this is justice to the man. If the man has not shown evidence of syphilis in the Army and you find the Wassermann positive, it goes down in the history sheet, he has to go down and take treatment, and if he refuses to do so it goes down on his chart and so becomes public property. The returned man, unless there are marked lesions, should be gotten out of the Army and in that way protected. If he is in the hospital his wife and friends come to see him, and everyone soon knows that he is attending a clinic for venereal disease if that plan of treatment is adopted. I do not believe in the long treatment of syphilis while the men are in the Army. If you can get the lesions cleared up, send them back to the trenches as soon as possible. They have $a^{\text {c }}$ much right to be there as the healthy, sound men. 
Dr. A. Schuyler Clark, New York: I have been in the Army for one year and up to the present time have never given a pink pill. My work has been entirely administrative and has consisted for nine months of medical administrative work in a division and three months in a base hospital, so I am inclined to look at this question from the point of view of efficiency in the Army and of administration. 'The point of putting a case of venereal disease in the hospital has two sides. There is no question that every acute case should be in the hospital, but there is a very decided objection to keeping them in the hospital too long. There is a great tendency for some soldiers to get "hospitalitis" or become hospitalized, and once that has happened it is extremely hard to get them interested in an organization again and anxious to go to the front, as all our soldiers are. A member of our organization is doing most efficient work at Camp Grant. I refer to Major W. L. Baum. The idea of getting venereal patients out of the hospital and having them treated by their organization is being urged by him. It is being tried out at the present time at the Depot Brigade at our cantonment, where they receive the new men coming directly from civil life. A venereal infirmary is being established there for the treatment of venereal patients in order that they may be gotten out of the hospital as soon as the acute stage is over. I am convinced that from the point of view of efficiency in the Army this plan is along the proper line. I believe that soom a division infirmary will be organized and there it will be important for an experienced venereal surgeon to teach the treatment of venereal diseases to the regimental officers of the detachment, requiring at least one regimental officer to report at this venereal infirmary and learn how to take care of venereal cases. I think that will be a future development in the Army. It is now being put into effect at Camp Grant. These soldiers do not wish to become hospitalized. I should like to tell you how appreciative the officers at Camp Grant are relative to the efforts being made to prevent prostitution in Rockford. I have never seen a cleaner city than is Rockford. It is rare to find a so-called new venereal case. The women of Rockford meet the trains and a questionable woman is approached by these women and advised that she had better return where she came from. If this is not effective, supervision is kept over her, and sooner or later she is put in jail or gotten out of town. This has a splendid effect on the cantonment in the prevention of venereal disease. There is no question about the effectiveness of prophylaxis. Another element which I consider of very great importance is the abstinence from alcohol.

Dr. Henry R. VArney, Detroit: Dr. King Smith was speaking of the proper treatment of the returned soldier, but I think there is another point, and that is the duty we owe to the returned soldier's family. I should like to ask what is being done to prevent these returned soldiers from infecting their wives and children with gonorrhea and syphilis.

Dr. Fred Wise, New York: As I have the good fortune to be one of the few men in the room who is associated with Dr. Fordyce, I will confine my remarks to a discussion of his paper. In his recent writings his aim has been a campaign of education for the physician more than for the layman. The question of neurosyphilis has occupied his time for several years, but in spite of the fact that he has an overwhelming supply of data to present it may surprise you to know that in our city of New York many doctors not only do not follow his precepts in the treatment of neurosyphilis, but actually decry the value of spinal punctures. Dr. Fordyce's reports are based not on imagination, but on careful scientific data which have accumulated after years of hard labor. Naturally I can appreciate the work which he has presented to you today, because I have before me every day the results of the spinal treatment of neurosyphilis. If the handwriting on the wall be interpreted correctly, every doctor, specialist or practitioner will not only have to master the subject of spinal puncture in every case of syphilis, but also the treatment of neurosyphilis on the lines laid down by Dr. Fordyce.

Dr. James Herbert Mitchell, Chicago: Many of the criticisms of intraspinal methods are incident to the dangers of that treatment. The original Swift-Ellis technic was designed for those cases which did not respond to the intravenous method. In our work we have limited our cases to those which did not respond to other treatment. The criticism which Dr. Stokes brings against the method will apply equally as well to the intravenous method. We have all seen a great many cases which have been markedly mistreated with the intravenous technic. That is not a criticism of the method, but of the clinician. During the past year I saw a patient in the dispensary who had had eight intravenous treatments. She had a hemiplegia and intense headache, which was not in any way relieved by intravenous injection. Spinal puncture showed 1,000 cells per cubic millimeter. One intraspinal injection of a large dose of undiluted serum gave her relief from the headache, and two further treatments relieved practically all the objective as well as the subjective symptoms.

Dr. Loyd Thompson, Hot Springs, Ark.: I wish to mention one or two things in regard to venereal prophylaxis in the Army which Dr. Pusey did not touch on, the enlisted man on furlough and the officer on leave of absence. I found that 8 per cent. of our men who contracted the disease did so while on furlough. We are not able to control their actions on those occasions, and they have no prophylactic material with them. It is my idea that it would be a good plan to furnish all men who go on furl ugh with a prophylactic kit of some sort. A man may go on pass one night and indulge himself and come hack and fail to take the prophylaxis. He will go on pass again the next night, will not indulge himself, but will take the prophylaxis. He is within the law, so far as the Army regulations are concerned, and we have no way of knowing when the infection occurred.

In the matter of treatment: As long ago as last October I advocated establishing dispensaries in the divisions. Our division surgeon did not approve of it and we did not get as good results as we might have. We have now established a division dispensary which will take care of all ambulatory cases of venereal disease.

Dr. M. Scholtz, Cincinnati : In discussing sanitary control of venereal diseases we must differentiate clearly between the military and civic aspects. The military problem is so thoroughly and efficiently controlled by the federal government that we, as physicians, have no cause for anxiety as to the results sought for. The civilian problem is infinitely more difficult and complex. We should realize that the main reason why the venereal problem is so difficult of solution is because venereal diseases are social and secret. The medical profession as a body cannot render a greater service to society than by educating and molding its mind in this direction. When we have accomplished this our difficulties will largely cease. I believe, in this sanitary crusade of social hygiene, we should rely more on the educational campaign and more liberal attitude in the matter than on the oppressive legislation or on the raids on shady hotels. We should not judge the effectiveness of our clean-up efforts by the number of arrested women of ill repute. The effects of these measures are always transitory and local in character. We all know that these undesirable female characters, when driven out of one city, land in another community. We simply transfer our burden temporarily to our neighbors. From this viewpoint it is high time for the medical profession to urge the government to organize a national commission for the study of venereal diseases from every possible angle-medical, social, educational and economic--a commission which would insure a concerted action on the national scale and rational methods of solution.

Dr. E. H. Martin, Hot Springs, Ark.: Referring to Dr. Brown's paper, I wish to call attention to one factor which may have led to error; that it, that his experiments were made on rabbits with the initial lesion. Any one who has treated many cases of chancre must realize that the chancre is the most resistent of all syphilitic lesions to treatment until you come to the cerebrospinal colonies. Many organisms reside in the chancre, many of them in an unkillable stage, and the drug does not have the effect on them that it does on the ordinary forms of spirochete. Very often an indurated lump will remain at the site of the chancre for weeks after healing; very often ten doses of ordinary arsphenamin have been given 
licfore such a lump would soften. I believe if the experiments could be carried out on animals in the secondary stage, after the chancre had softened, they would be more valuable in determining which of the drugs is most curative.

Dr. FrankLIN R. Wright, Minneapolis: If we may believe the writings of Havelock Ellis, there has been only one race of people discovered who did not have prostitutes, and they had polygamy. The question simply comes down to one of sex; the male has strong sexual desires, while the female has maternal desires. Applied to the human race, the male is a natural Mormon and the female is not. It is simply a matter of sex all the way through. One of the leaders on sex questions has stated that if a man of 35 brags that his will is so strong that he has never had intercourse, that man is boasting of the weakness of his sexual powers instead of l,ragging of the strength of his will power. The question is, Are we willing to teach the general public that all unmarried men have intercourse, and that the state has cured all persons having illicit intercourse of contagious disease and made fornication as safe as possible? Are we ready to go so far as to teach the public that there are measures which they can take by which the chances of infection are reduced to the minimum? If we are ready to teach the young boys and girls these things, well and good. The Army is a different proposition. It is a well-known fact that the men who do the heavy physical work are not the ones that have strong sexual desires. The men who do the mental work and live sedentary lives are the ones who have the strong desires. Army life is a fairly active life.

There are reasons why the Army shows great diminution in the amount of venereal disease. All these cantonments are in small communities. The number of prostitutes in any community is in proportion to the number of unmarried males. More than this number cannot find lodging suitable to their vocation. This is the situation at Rockford, I1l.; Battle Creek, Mich.; Camp.Kearney at San Diego, Calif., and other places. At Camp Custer, Mich., between October 1, 1917, and December 15, 1917, there was only one young man admitted to the Base Hospital who had acquired his infection after entering the Army. There were no prostitutes at these places, except a few to take care of the needs of the unmarried men among the 30,000 people living in Battle Creek. This reason will apply to Camp Kearney, Calif., the same as at Camp Custer, Mich.

Dr. Wade H. Brown, New York: In experimental therapy we have to take such conditions as we find them and make the hest use of them. As to the use of the rabbit for experimental purposes, well developed and enduring primary lesions are relatively easily obtained, while there has been a great deal of discussion as to the extent to which a true generalization of the infection with secondary lesions follows a local inoculation. In recent years we have found that a true generalized syphilis does occur in the rabbit in many instances and that secondary lesions may appear even as late as sixteen or eighteen months after inoculation, but such lesions may be very transient and, as a rule, are much more easily influenced by treatment than the primary lesions. Further, when treatment is instituted during the primary stage of the infection with consequent healing of the initial lesions, if a true cure has not been effected, secondary or generalized lesions may appear later in a considerable number of animals and this is particularly true of certain drugs, as instanced by the results reported with various arsphenamin preparations. For these and other reasons which we might mention, it seems better as a routine procedure to treat experimental animals during the primary stage of the infection and to rely on the subsequent development or absence of generalized lesions during some four to six months than to treat the more transient and more easily influenced secondary lesions. Under the circumstances, this is all one can do, as a rule, and the results obtained from such experiments furnish reliable presumptive evidence as to the therapeutic action of the drugs used.

Dr. William Allen Pusey, Chicago: I would like to call Dr. Wright's attention to the fact that the reason there are not more women in Rockford and Battle Creek is not because there are not more prostitutes that might be available for these districts, but because it is a part of the Army work to keep them away.

Regarding the question about what to do with cases of venereal diseases after the war, this is undoubtedly very important, but so far there has been considerable to do to take care of the venereal cases during the war, and not much has been done as yet toward the care of them after the war. The protection of the family against venereal disease while the man is in the Army is pretty well taken care of by the fact that these men are not allowed to get away.

Regarding the percentage of venereal disease, the Army program has taken some pride in the fact that it has not been an unworkable program. I do not mean that it is ideal, but only a fair standard at the present time.

Dr. John A. Fordyce, New York: I had no intention of presenting the subject of intraspinal therapy in neurosyphilis, but as this has been touched on by several of the gentlemen I will briefly refer to it. In order to obtain results by the method in question one must have a very clear conception of the various conditions present. In other words, indications for or against this therapeutic procedure are afforded by the results obtained from an examination of the spinal fluid. Early meningitis may occur before, during or after intensive treatment. These cases can best be controlled by intraspinal injections. In tabes, with a relatively high cell count and positive Wassermann, if the degeneration be not too far advanced, we can anticipate further degeneration, relieve the pains and cure the crises in the majority of cases. In optic atrophy, with the preservation of one half or one third of the vision with positive findings in the fluid, we can arrest in the majority of cases the further progress of the atrophy.

Many neurosyphilis patients come to me in my private work and in the clinic who have had a large amount of treatment of arsphenamin and mercury. It is useless to continue the ordinary methods of treatment in such cases. They are treated intraspinally if the indications afforded by the spinal fluid examination point to an involvement of the meninges. Many cases of disseminated cerebrospinal syphilis which have not been cured by ordinary treatment have been cured or greatly benefited by the method in question. In the past five years we have treated about 170 cases of various types of neurosyphilis and have obtained a negative cell count and negative Wassermann in 2.0 c.c. of fluid in about 30 per cent. of the cases. We do not consider the patient cured until we obtain a negative Wassermann with the larger quantities of fluid. As to the benefit to be expected in paresis we cannot say as much. There are, however, borderline cases of meningoencephalitis which simulate paresis and which have been cured. In the routine examination of the spinal fluid in the various types of neurosyphilis we frequently meet with patients who give a four plus $(++++)$ Wassermann in 0.2 c.c. and a paretic colloidal gold curve. Although these cases presented no stigmata of degeneration, we consider them potential paretics. In these cases treatment probably delays for a long time the development of the later degenerative stage.

Dr. HARRY G. IRvine, Minneapolis: In regard to the returned soldier, the federal government should notify the state boards of health of any diseased man coming into their district. Where the program which has been suggested is enforced it would be possible to have these cases taken care of in their dispensaries. This program provides for this very thing and not only for the care of the returned soldier, but will also protect his family and the community as necessary. I am sure that the Surgeon-General's Office has gone into this matter and that it will be given serious consideration. The relationship of prostitution to venereal disease can hardly be settled in two or three minutes' discussion. It is possible to do away with commercialized prostitution, which is not in business to take care of the demand but to create a demand, and this can and should be done away with. So far as control of prostitution is concerned, it is worthless to institute any form of medical examination to attempt to make it safe. In any attempt at regulating prostitutes it has never been possible to register more than 10 per cent., and it is worthless to adopt any program which can be applied to those registered and not to the others, who are in the majority. So I cannot see that 
it will ever be possible to make the prostitute safe, so far as venereal disease is concerned. I think that the habits of the male have a great deal to do with the amount of intercourse. If a man is in the habit of doing without for a long time he can do so very nicely. The question of alcohol, whether a man is working or not, and the nature of his work all enter into it very largely, but as time goes on and we have better sociological conditions we will likely develop a race of men who will get along with much less intercourse than has been the case in the past, even if such a thing is not the case at present.

The question of making prostitution safe brings up again the segregated district, and that has been shown to be an absolute failure, so far as venereal disease is concerned. Many of the best authorities have gone on record, publicly stating it as their opinion that any attempt at medical regulation has always been a failure so far as reducing venereal disease is concerned. I think that until we are as well informed as those men are it is hardly good form for us to question the statements which they make.

\section{THE QUESTION OF OPERATION IN GUNSHOT ABDOMINAL WOUNDS *}

\section{JOSEPH RILUS EASTMAN, M.D. INDIANAPOLIS}

The study of gunshot wounds of the abdomen deals with one of the most interesting chapters of the major wounds of war, especially by reason of the numerous controversies relating to a general plan of treatment of abdominal wounds. Certainly the present war has developed important advances in this department of surgery.

In previous wars it was held as dogma that gunshot wounds of the abdomen should be treated expectantly and conservatively, as distinguished from the teaching of prompt operation in civil practice. At the present time, it may be said that the weight of opinion is in favor of applying in military practice the civil method of immediate operation in all penetrating wounds of the abdomen wherever the favorable conditions of civil practice can be provided. These essential conditions include a skilled operator, trained assistants, a sufficient armamentarium, an aseptic environment, and the time in which to operate. Practically all agree that it is better to await the establishment of these conditions before attempting to operate.

It is likely that the best explanation of the improved statistics of operation in this war is to be sought in the favorable conditions of trench warfare, the battle lines being in the main more stable than in former wars, and allowing of better preparation for operating near the front.

Chalier and Glénard ${ }^{2}$ express the view of most war surgeons in all armies when they say that expectancy is a "snare and a delusion." It is permissible only when twenty-four to forty-eight hours have elapsed since the injury, when operation could do no good. In this event, they advise that no food should be given and the man should not be sent back any distance until after six weeks.

Notwithstanding the fact that the experiences of the present war have modified the old views as to the advisability of abstention in abdominal

* Read before the Section on Obstetrics, Gynecology and Abdominal Surgery at the Sixty. Ninth Annual Session of the American Medical Association, Chicago, June, 1918.

1. Chalier, André, and Glénard, Roger: Rev. de chir., 1917, 53, 124. wounds, there still remains, notably in France, a rathe' sharp division between what are designated the abstentionists on the one hand and the interventionists on the other. The former group bases diagnosis of penetration and perforation, as well as treatment, on the evolution of symptoms; the latter group makes the complete diagnosis by laparotomy, applying appropriate surgical treatment immediately or within the first few hours. Unfortunately, the most experienced surgeons occasionally find more or less difficulty in diagnosticating penetration and perforation before operation, and all are, of course, opposed to precocious operating in nonpenetrating wounds.

There is not always present an aperture of exit, in which case it is difficult to determine the course of the missile. All missiles may ricochet. I have witnessed wounds in which, if the missile had traversed the shortest route between the two openings, there would have been perforation of many vital organs and structures, and yet there was no serious injury.

There are a few recognized rules to follow; for example, the closer together the wounds of entrance and exit, the less the chance of penetration. And Rochard $^{2}$ declares that if a wounded man does not cease to complain of abdominal pain, a perforation is almost certain. Rochard also says that if a patient passes gas at the anus, there is no perforation.

All rules fail sometimes, with the exception of these three which prove the existence of perforation: escape of bowel contents from the wound of entrance or exit, protrusion of perforated intestine at the wound, and passing of the missile by the anus. Schwartz and Mocquot ${ }^{3}$ describe four cases of perforation showing no signs. I have observed the case of a man with perforating wound of the abdomen who continued active duty for several hours after receipt of the wound, having no knowledge of the injury. Six hours after injury, the abdomen at operation was filled with blood.

Among the common signs of perforation are pain; vomiting; hiccuping; costal breathing, due to immobility of the diaphragm; the syndrome of shock; boardlike rigidity of the abdomen (ventre du bois) ; retraction of the testicle to the external abdominal ring; change in shape of the abdomen, for example, the "ventre bilobé" from meteorism; emphysema as in colon wounds; tympany; temperature changes, etc. To these may be added the symptoms of intraabdominal hemorrhage. A true interventionist does not, of course, a wait the appearance of all these symptoms, since one may suffice to determine the propriety of operating.

\section{CONDITIONS DETERMINING OPERABILITY}

Among the deciding criteria which determine the advisability of operation are the following:

1. The kind of missile. A smooth undeformed bullet as a rule makes a small canal in the abdominal wall and a small easily sutured opening in a hollow viscus unless the shot be tangential to the intestine. Such a smooth bullet, however, usually produces an irregular laceration of a parenchymatous organ. The aperture of entrance being smaller and more clear cut than the aperture of exit. Irregularly deformed bullets naturally produce larger and more ragged wounds than do smooth ones. For example, the fragmented nickel or steel mantle partially split off and projecting from a lead center bullet may do great damage. Large

2. Rochard, E.: Bull. et mem. Soc. de chir. de Paris, 1915, 41, 2182. 51, 56 . 